\title{
Formulation and Evaluation of Phytosome-Loaded Maltodextrin-Gum Arabic Microsphere System for Delivery of Camellia sinensis Extract
}

\author{
Effionora Anwar*, Nadira Farhana \\ Faculty of Pharmacy, Universitas Indonesia, Depok, West Java, INDONESIA.
}

\begin{abstract}
Background: Phytosome is a nanovesicle that combines plant extracts and phospholipids to produce more soluble fat complex and provide better absorption. The Camellia sinensis (green tea leaf) extract has an abundant amount of polyphenol-containing Epigallocatechin gallate (EGCG). However, its absorption properties are poor due to its high polarity, and it is unstable to heat, light, and $\mathrm{pH}$. The purpose of this study was to formulate and produce a phytosome-loaded microsphere of green tea leaf extract with good physicochemical properties, so it can improve the stability and delivery of phytosome. Methods: Phytosome was made using thin layer hydration method. It was formulated with green tea leaf extract equal to $3 \%$ of EGCG, and different concentrations of $97 \%$ phospholipids containing $30 \%$ phosphatidylcholine (lipoid P 30), i.e. 2\% (F1); 3.5\% (F2); and 4\% (F3). The selected phytosomes were formulated into a microsphere using maltodextrin and gum arabic as a carrier, then their stability and dissolution profile were evaluated. Results: The results showed that F3 was the best formula with spherical shape, Dmean volume of $42.58 \mathrm{~nm}$, polydispersity index at 0.276 , zeta potential at $-48.2 \pm 1.78 \mathrm{mV}$, and entrapment efficiency of
\end{abstract}

$50.61 \pm 0.93 \%$. Total cumulative amount of EGCG after $4 \mathrm{~h}$ dissolution test was $85.21 \%$. Furthermore, it showed a good physicochemical stability through organoleptic, water content, and physicochemical properties study which was conducted for 6 weeks at various temperatures. Conclusion: In conclusion, phytosome-loaded maltodextrin and gum arabic microsphere of green tea leaf extract could increase the stability of EGCG.

Key words: Camelia sinensis extract, Epigallocatechin gallate (EGCG), Gum arab, Maltodextrin, Microsphere Phytosome.

\section{Correspondence}

Effionora Anwar, Faculty of Pharmacy, Universitas Indonesia, Depok, West Java 16424, INDONESIA.

Phone: +62217270031

Email: effi.nora@gmail.com

DOI: 10.5530/jyp.2018.2s.11

\section{INTRODUCTION}

Indonesia is mentioned as the fifth largest exporter of tea in the world after Kenya, Sri Lanka, India, and Vietnam. However, the amount of tea production is not supported by the use of technology to process the tea into a high-quality material. ${ }^{1}$ One type of tea that widely consumed is green tea. The results of several studies suggest that green tea may help cure diabetes, Inflammatory Bowel Disease (IBD), cancer, liver disease, and weight loss. ${ }^{2}$ The most widely contained compound in green tea is polyphenols, which is about one-third of the total $94.5 \%$ of bioactive compounds. The most widely contained polyphenols are catechins. Among other catechins, epigallocatechin gallate (EGCG) is the most active molecule for antioxidant properties. ${ }^{3}$

EGCG has a hydrophilic property with a water solubility of $521.7 \mathrm{~g} / \mathrm{L}$ and a partition coefficient ( $\log \mathrm{P}$ ) of $0.48 .{ }^{4}$ Use of EGCG via oral route shows a very low absorption, i.e. less than $5 \% .{ }^{5}$ This very low absorption is due to the polyphenol structure which has many $\mathrm{OH}$ groups, making it too polar to penetrate the intestinal lipid membrane. ${ }^{6}$ In addition, EGCG is a substrate of multidrug resistance-associated proteins (MRP 1 and 2). MRP is an ATP-dependent efflux transporter. MRP 2 can reduce EGCG bioavailability by removing it back into the intestinal lumen, soit can't reach systemic circulation.?

EGCG absorption and bioavailability problems can be overcome by formulating green tea extract into a lipid-like carrier such as phytosomes. Phytosomes are nanovesicles that combine plant extracts and phospholipids to produce fat-soluble complexes. Phytosomes are also carriers that can increase the therapeutic efficacy of the green tea leaf extract. ${ }^{8}$ Phytosomes have better abilities than herbal extracts in terms of their absorption through the intestinal lipid membrane. ${ }^{9}$ In addition to its absorption and bioavailability problems, EGCG also has limitations on its stability, i.e. sensitive to heat, light, and $\mathrm{pH} .{ }^{10}$ The problem can be solved by formulating the phytosomal suspension into a microsphere. Another reason the phytosomal suspension made into a microsphere is the long-term stability problem of suspension. Suspension stability will gradually diminish in long-term storage because crystal formation may occur due to rising room temperature, which may lead to an increase in particle size in the suspension. Changes in particle size in the suspension may affect the therapeutic effect of the dosage form. ${ }^{11}$

Phytosomal suspension of green tea leaf extract will then be made in the form of microspheres by the spray-drying method, which is suitable for polyphenol compounds that are sensitive to heat because of its rapid process. ${ }^{12}$ The rapid drying process of a spray dryer is due to the formation of droplets with the large surface area after the atomization stage, which expands the area exposed to heat. The carriers used are maltodextrin and gum arabic. Maltodextrin was chosen because it is an excellent heat protector so it can protect EGCG in thespray-drying method. ${ }^{10}$ Maltodextrin is often combined with gum Arabic. These combinations show satisfactory results by generating entrapment efficiency up to $85 \%$ in previous studies. ${ }^{13}$

In this study, phytosome-loaded microsphere of green tea leaf extract (PM) was prepared and evaluated. The evaluation was morphology, size, 
particle size distribution, efficiency of absorption, moisture content, dissolution, and stability.

\section{MATERIALS AND METHODS}

\section{Materials}

Green tea leaf extract (Camellia sinensis L. Kuntze) (Andy Biotech Co. Ltd., China), EGCG standard (Sigma-Aldrich, Singapore), Lipoid P 30 with purity of $97 \%$ phospholipids containing 30\% phosphatidylcholine (kindly provided by Lipoid GmbH, Germany), 2,2-Diphenyl-picryl hydrazine (Sigma Aldarich, Singapura), ascorbic acid (Sigma Aldrich, Singapore), solvents and other chemical reagents are analytical grade.

\section{EGCG assay in green tea leaf extract}

A calibration curve was made with a standard solution of EGCG, and the sample solution concentration was $40.0 \mu \mathrm{g} / \mathrm{mL}$. EGCG analysis was carried out in a High-Performance Liquid Chromatography (HPLC) system and using a C18 Shimpack column with a UV-vis detector set at $280 \mathrm{~nm}$. C18 column with a flow rate of $1.0 \mathrm{~mL} / \mathrm{min}$ was used. The mobile phase consisted of acetic acid $(0.05 \%, \mathrm{v} / \mathrm{v})$ : acetonitrile $(87: 13, \mathrm{v} / \mathrm{v})$. The injection volume was $20 \mu \mathrm{L}$ and a total run of $17.5 \mathrm{~min}$.

\section{Antioxidant Activity Test of Green Tea Leaf Extract}

Green tea leaf extract solution and the positive reference solution of ascorbic acid were made in different concentration. $100 \mu \mathrm{g} / \mathrm{mL} \mathrm{DPPH}$ $(1.0 \mathrm{~mL})$ and methanol $(2.0 \mathrm{~mL})$ were added into $1.0 \mathrm{~mL}$ of each sample solution. The mixture was shaken with vortex for a few sec, then incubated at a room temperature of $28^{\circ} \mathrm{C}$ for $30 \mathrm{~min}$. The antioxidant activity was determined by measuring the absorbance of each sample using UV-Vis spectrophotometer with an optimum wavelength of $514 \mathrm{~nm}$.

\section{Phytosome Formulation}

Phytosome formulations can be seen in Table 1. Phytosome was prepared using thin-layer hydration method. First, Lipoid P 30 was diluted with dichloromethane, while the green tea leaf extract was diluted with $90 \%$ ethanol. Then, both the dissolved phospholipid and green tea leaf extract were poured into the round-bottom flask. The dichloromethane was evaporated using rotary vacuum evaporator at $37^{\circ} \mathrm{C}$ at gradual speed started in 25 to $150 \mathrm{rpm}$, and vacuumed until an even and firm thin layer was obtained. Nitrogen gas flowed into the thin layer, then the layer was stored in the refrigerator up to $24 \mathrm{~h}$. The thin layer was then hydrated with phosphate buffer $\mathrm{pH} 5,5$ at $40^{\circ} \mathrm{C}$. Once the phytosomal suspension was formed, ultrasonication was done for $2 \mathrm{~min}$.

\section{Phytosome Characterization \\ Morphology}

Phytosome morphology was analyzed using transmission electron microscope (TEM). One drop of sample was shed on a carbon-coated copper grid sized $400 \mathrm{~nm}$ and dried at room temperature. Then, it was colored using phosphotungstic acid solution. After completely dried, the sample was analyzed under the microscope on 80000x magnifications with the acceleration voltage of $100 \mathrm{kV}$.

Table 1: Phytosome formulas.

\begin{tabular}{cccc}
\hline & \multicolumn{3}{c}{ Concentration (\%) } \\
\cline { 2 - 4 } Materials & F1 & F2 & F3 \\
\hline Green tea leaf extract $(\mathrm{mg})$ & 1413 & 1413 & 1413 \\
Lipoid P30 (mg) & 1250 & 1875 & 2500 \\
Phosphate Buffer pH 5,5 (ml) & ad 25 & ad 25 & ad 25 \\
\hline
\end{tabular}

\section{Particle Size Distribution, Polydispersity Index and Zeta potential}

Particle size distribution and zeta potential of phytosome formulas were measured using Dynamic light scattering (DLS) particle size analyzer with a computerized system (Malvern, Zetasizer). Zeta potential and polydispersity index measurements were also performed.

\section{Fourier Transform Infrared (FTIR) spectroscopy}

To investigate the interaction of green tea leaf extract and phospholipids in green tea leaf extract phytosomal suspension, FTIR spectra were measured using a FTIR microscope. Infrared spectra of the test samples were determined using the $\mathrm{KBr}$ disc technique. The FTIR measurements were performed in the scanning range from 4000 to $400 \mathrm{~cm}^{-1}$. Green tea leaf extract, lipoid P 30 , the mixture of green tea leaf extract and lipoid $\mathrm{P} 30$, and the freeze-dried phytosome were analyzed.

\section{The Entrapment Efficiency of Phytosome}

The proportion of encapsulated EGCG was determined by centrifuging $0.5 \mathrm{~mL}$ of the phytosome formulation at $14000 \mathrm{rpm}$ for $90 \mathrm{~min}$ at room temperature. The supernatant was taken carefully using pipette. Pure supernatant was then dissolved in ethanol to disrupt the vesicles, then appropriate dilution was made to measure the EGCG content using HPLC (Shimadzu) at $280 \mathrm{~nm}$. Entrapment efficiency was calculated by the equation below:

$\% \mathrm{EE}=\frac{\text { Total EGCG in suspension }- \text { EGCG concentration in the sup erna tan }}{\text { Total EGCG in the suspension }} \times 100$

\section{Phytosome-Loaded Microspheres Preparation}

Phytosome-Loaded microspheres formulations can be seen in Table 2. Microsphere was prepared by firstly dissolving the gum arabic (26.72\%) in aqua demineralisata at $50-60^{\circ} \mathrm{C}$, then adding the maltodextrins $(40.12 \%)$. EGCG (33.16\%) was then added to the solution at room temperature, with constant homogenization at $100 \mathrm{rpm}$ with a dispersing device Omni-Multimix Inc. The mixture was spray-dried in an atmospheric pilot spray-dryer operated at an air inlet temperature of $125 \pm 5^{\circ} \mathrm{C}$ and outlet $60 \pm 5^{\circ} \mathrm{C}$ to obtain the formulation in powder form. Spray-dried phytosome or Phytosome Powder (PP) without maltodextrin and gum arabic were prepared by the same method.

\section{Phytosome-Loaded Microspheres Characterization The Entrapment Efficiency of Microspheres}

Two hundred mg of PM was dispersed in buffer $\mathrm{pH}$ 5.5. The dispersion was added into the centrifugal tube and vortexed for 1 minute. The dispersion was centrifuged at $9.500 \mathrm{rpm}$ for 10 minutes. One milliliter of supernatant was taken and added to volumetric flask $(10 \mathrm{ml})$, the volume was adjusted using buffer pH 5.5 (Sol. 1). $1 \mathrm{ml}$ of Sol. 1 was added to another volumetric flask $(10 \mathrm{ml})$ and the volume was adjusted (Sol. 2). $1 \mathrm{ml}$ of the Sol. 2 was added to a volumetric flask $(5 \mathrm{ml})$ and the volume was adjusted using ethanol (Sol. 3). Sol. 3 was filtered using filtering syringe $0.45 \mu \mathrm{m}$, then analyzed using HPLC at the maximum wavelength of $280 \mathrm{~nm}$.

Table 2: Microspheres formulas.

\begin{tabular}{cccc}
\hline Materials & \multicolumn{3}{c}{ Concentration (gram) } \\
\cline { 2 - 4 } & PM & PP & EM \\
\hline Green tea leaf extract phytosome & 8,3 & 8,3 & 8,3 \\
Gum arabic & 6,68 & - & 6,68 \\
Maltodextrin & 10,03 & - & 10,03 \\
\hline
\end{tabular}


Total EGCG was determined by dispersing $200 \mathrm{mg}$ of PM in buffer $\mathrm{pH}$ 5.5. The dispersion was added into the centrifugal tube, vortexed for 1 minute, and sonicated for 20 minutes. $1 \mathrm{ml}$ of solution was taken, $2 \mathrm{ml}$ of chloroform and $3 \mathrm{ml}$ of ethanol were added to disintegrate the vesicle (Sol. 4). $1 \mathrm{ml}$ of Sol. 4 was added to a volumetric flask and the volume was adjusted with ethanol and then analyzed using HPLC. The entrapment efficiency was calculated using the following formula:

$\% \mathrm{EE}=\frac{\text { Total EGCG in the microspheres }-\mathrm{EGCG} \text { concentration in the supernatan }}{\text { Total EGCG in the microspheres }} \times 100$

\section{Particle Size and Morphology of Microspheres}

Particle size distribution and zeta potential of microspheres were measured using Dynamic light scattering (DLS) particle size analyzer with a computerized system (Malvern, Zetasizer). Zeta potential and polydispersity index measurements were also performed.

The morphology of microspheres was evaluated using scanning electron microscopy (SEM). The microspheres were suspended in absolute alcohol and sonicated for $5 \mathrm{~s}$ to break up the aggregates. One drop of suspension was spread onto an aluminum stub covered with double-sided adhesive tabs. After the alcohol evaporated completely, the microspheres were vacuum-coated with a gold-palladium film and analyzed with SEM (FEIINSPECT F50).

\section{Degree of Swelling of Microspheres}

Pre-weighed microspheres $(100 \mathrm{mg})$ were placed into a centrifugation tube containing $10 \mathrm{~mL}$ of phosphate buffer $\mathrm{pH} 5,5$. The content was allowed to swell for $240 \mathrm{~min}$. Samples at minute 60, 120, and 240 was centrifugated at 4000 for 10 minutes. The obtained supernatant was then discarded so that swollen sample can be weighed.

The percentage degree of swelling of the microspheres was determined using the equation below:

$$
\text { Percentage }(\%) \text { of swelling }=\frac{\mathrm{wt}-\mathrm{w} 0}{\mathrm{w} 0} \times 100 \%
$$

where Wt represents the weight of the swollen sample at the stipulated time in the simulated fluid and the initial weight of microparticles before swelling is WO.

\section{Moisture Content}

Measurement of moisture content was done using a moisture balance analyzer. A thousand milligram of microspheres were placed on top of the aluminum container and then the measurement was made at $105^{\circ} \mathrm{C}$. The readable value of the device was recorded as the microsphere moisture content. The moisture was calculated using the equation:

Percentage $(\%)$ of moisture content $=100 \%$-results obtained from the device (\%)

\section{In vitro drug release studies}

The fluid used for the study was $\mathrm{pH} 7.4$ phosphate buffer as simulated intestinal fluids. Samples were incubated at $37^{\circ} \mathrm{C}$ using $100 \mathrm{~mL}$ beaker glass at $100 \mathrm{rpm}$ and the microspheres were put into a membrane. After time intervals of $0,10,15,30,45,60,120,180$ and $240 \mathrm{~min}$, aliquots from simulated solutions were withdrawn to determine the EGCG concentration using HPLC methods. The result was reported as EGCG if the green tea leaf extract was able to cross the membrane. The dissolution test was also conducted on PP and green tea leaf extract microspheres (EM). The sample tested was also performed TEM test to see the existence of phytosome in the microspheres.

\section{Stability Study of Microspheres}

Stability tests were performed to see the effect of microspheres on the stability of green tea leaf extracts. Color, moisture content and antioxidant activity were analyzed. In this study, stability tests were performed on PM compared with PP at low temperature $\left(4 \pm 2^{\circ} \mathrm{C}\right)$, room temperature $\left(28 \pm 2^{\circ} \mathrm{C}\right)$, and high temperature $\left(40 \pm 2^{\circ} \mathrm{C}\right)$. The moisture content test was performed at the first and last week. The antioxidant activity test on both samples was done once a week for 6 weeks.

\section{RESULTS}

\section{EGCG assay in green tea leaf extract}

EGCG peak appeared after $17 \mathrm{~min}$. Based on the analysis, the area obtained was then calculated into the calibration curve, so the content of EGCG in the extract was $53.08 \%$.

\section{Antioxidant Activity Test of Green Tea Leaf Extract}

The $\mathrm{IC}_{50}$ value of green tea leaf extract was $1.37 \mu \mathrm{g} / \mathrm{mL}$, while the $\mathrm{IC}_{50}$ value of ascorbic acid was $2.88 \mu \mathrm{g} / \mathrm{mL}$.

\section{Morphology}

Based on the TEM results, F3 had the most spherical shape compared to F1 and F2

\section{Particle Size Distribution, Polydispersity Index, and Zeta potential}

The results for particle size, zeta potential, and polydispersity index can be seen in Table 4 . Dv10 value can be interpreted as $10 \%$ of the total particles were smaller than the value. The same interpretation was used to describe dv50 and dv90. These data can be seen in Table 3. PDI value of phytosome formulas F1, F2, F3, respectively, were $0.194 ; 0.227 ; 0.276$. The zeta potential values of F1, F2, and F3 were respectively; $-41.3,-47.9$ $\pm 3.43 ;-48.2 \pm 1.78$

\section{Fourier Transform Infrared (FTIR) spectroscopy}

Based on the overlay spectrum image consisted of green tea leaf extract powder, Lipoid P 30, freeze-dried green tea leaf extract phytosome, and mechanical mixture between green tea leaf extract with Lipoid P30 in Figure 3, it can be seen that each sample gave $\mathrm{OH}$ peak at $3223.16 \mathrm{~cm}^{-1}$, $3325.19 \mathrm{~cm}^{-1}, 3173,01 \mathrm{~cm}^{-1}, 3325,39 \mathrm{~cm}^{-1}$.

Table 3: The distribution of particle size according to volume.

\begin{tabular}{cccc}
\hline Parameter & F1 & F2 & F3 \\
\hline Dv 10 (nm) & 32,9 & 27,2 & 16,3 \\
Dv 50 (nm) & 93,4 & 83,3 & 26,7 \\
Dv 90 (nm) & 215 & 218 & 80,9 \\
D $_{\text {mean }}$ Volume $(\mathrm{nm})$ & 111,63 & 104,75 & 42,58 \\
\hline
\end{tabular}

Table 4: Summary of phytosome characterization results.

\begin{tabular}{|c|c|c|c|c|c|}
\hline Formula & Morphology & $\begin{array}{l}D_{\text {mean }} \\
(\mathrm{nm})\end{array}$ & $\begin{array}{l}\text { Polydispersity } \\
\text { Index (PDI) }\end{array}$ & $\begin{array}{c}\text { Zeta } \\
\text { Potential }\end{array}$ & $\begin{array}{l}\text { Entrapment } \\
\text { Efficiency (\%) }\end{array}$ \\
\hline $\mathrm{F} 1$ & $\begin{array}{c}\text { Nonspherical } \\
\text { shape }\end{array}$ & 111,63 & 0,194 & $-41,3$ & $35,98 \pm 1,97$ \\
\hline F2 & $\begin{array}{c}\text { Nonspherical } \\
\text { shape }\end{array}$ & 104,75 & 0,227 & $-47,9 \pm 3,43$ & $44,22 \pm 0,76$ \\
\hline F3 & Spherical shape & 42,58 & 0,276 & $-48,2 \pm 1,78$ & $50,61 \pm 0,93$ \\
\hline
\end{tabular}


Table 5: The mean of changes of $I C_{50}$ each week at 4,28 , and $40^{\circ} \mathrm{C}$.

\begin{tabular}{|c|c|c|c|}
\hline \multirow{2}{*}{$\begin{array}{l}\text { Temperature } \\
\left({ }^{\circ} \mathrm{C}\right)\end{array}$} & \multicolumn{2}{|c|}{$\begin{array}{l}\text { The mean of changes of } \mathrm{IC}_{50} \text { each } \\
\text { week }\end{array}$} & \multirow[t]{2}{*}{$p$ value } \\
\hline & $\mathrm{PM}(\mu \mathrm{g} / \mathrm{mL})$ & $\mathrm{PP}(\mu \mathrm{g} / \mathrm{mL})$ & \\
\hline 4 & 0,133 & 0,09625 & 0,37 \\
\hline 28 & 0,030 & 0,139 & 0,11 \\
\hline 40 & 0,091 & 0,041 & 0,15 \\
\hline
\end{tabular}

Table 6: Moisture content (\%) in PM and PP.

\begin{tabular}{cccc}
\multirow{2}{*}{ Formula } & Temperature $\left({ }^{\circ} \mathrm{C}\right)$ & \multicolumn{2}{c}{ Week } \\
\cline { 3 - 4 } & & 0 & 6 \\
\hline \multirow{2}{*}{ PM } & 4 & & 6,41 \\
& 28 & 4,61 & 4,98 \\
& 40 & & 4,56 \\
& 4 & & 5,81 \\
PP & 28 & 5,41 & 4,77 \\
& 40 & & 4,17 \\
\hline
\end{tabular}

\section{The Entrapment Efficiency of Phytosome and Phytosome-Loaded Microspheres}

The entrapment efficiency obtained using the indirect method was 35.98 $\pm 1.97 \%$ for F1, $44.22 \pm 0.76 \%$ for F2, and $50.61 \pm 0.93 \%$ for F3.

\section{Particle Size and Morphology of Microspheres}

PM had dv10 value of $1520 \mathrm{~nm}$, dv50 of $1950 \mathrm{~nm}$, dv90 of $2510 \mathrm{~nm}$ and D mean volume of $1972.50 \mathrm{~nm}$.

\section{Degree of Swelling of Microspheres}

PM had a swelling index of $171.81 \%$ at 60 minutes, $217.65 \%$ at $120 \mathrm{~min}$ and $267.33 \%$ at 240 minutes. While PP had a swelling index of $288.08 \%$ at $60 \mathrm{~min}, 289.06 \%$ at $120 \mathrm{~min}$ and $325.90 \%$ at $240 \mathrm{~min}$. EM had a swelling index of $42.16 \%$ at $60 \mathrm{~min}, 120.62 \%$ at $120 \mathrm{~min}$ and $11.135 \%$ at $240 \mathrm{~min}$.

\section{In vitro drug release studies}

The test was performed on PP, PM, and, EM. Based on the curve below (Figure 4), it can be seen that EM showed the fastest release with the percentage of cumulative EGCG release of $113.66 \%$ at the $4^{\text {th }} \mathrm{h}$, followed by $\mathrm{PM}$ of $85.21 \%$, and PP of $64.30 \%$.

\section{Stability Study of Microspheres Antioxidant Activity}

Based on $T$ test between two variables with mean values of each variable that was done to the increase of $\mathrm{IC}_{50}$ every week in PM and PP showed that the difference in the increase of $\mathrm{IC}_{50}$ was not significant $(\mathrm{p}>0.05)$. The change in $\mathrm{IC}_{50}$ value can be seen in Table 5.

\section{Moisture Content}

PM had a moisture content of $4.6 \%$ at week 0 or right after it was made, while PP had a higher moisture content of $5.41 \%$.

\section{DISCUSSION}

\section{EGCG assay in green tea leaf extract}

The mobile phase used was $0.05 \%$ glacial acetic acid - acetonitrile (87:13) which is polar, so it can drag the green tea leaf extract solution which is also polar. EGCG peak appeared after $17 \mathrm{~min}$. The injected sample concentration was $40 \mu \mathrm{g} / \mathrm{mL}$. Based on the analysis, the area obtained was then calculated into the calibration curve, so the content of EGCG in the extract was $53.08 \%$.

\section{Antioxidant Activity Test of Green Tea Leaf Extract}

The smaller the $\mathrm{IC}_{50}$, the higher the antioxidant activity of a compound. The result showed that green tea leaf extract has a stronger antioxidant activity than ascorbic acid. Compounds with an $\mathrm{IC}_{50}$ of $1.10-9.50$ have a strong antioxidant activity. ${ }^{14}$ Based on that statement, it can be concluded that both of ascorbic acid and green tea leaf extract have strong antioxidant activity.

\section{Phytosome Formulation}

Phospholipids were the main component of phytosome. Phospholipid is an amphiphilic molecule having a positive head group, and two neutral tail groups. The formation of a complex between phospholipids and EGCG will make EGCG has the solubility properties of phospholipids. ${ }^{6}$ The phytosomal complexes will increase the drug absorption thus increasing the bioavailability and increasing the number of compounds present in the systemic circulation. ${ }^{15}$

\section{Morphology}

Based on the TEM results, F3 had the most spherical shape compared to F1 and F2. The results were in accordance with the results obtained by Tung, Hai, and Son in 2017, ${ }^{16}$ where the vesicles formed have a spherical shape. The results were shown in Figure. 1.

\section{Particle Size Distribution, Polydispersity Index, and Zeta potential}

DLS method can also measure the polydispersity index (PDI). PDI value should be $<0,1$ for a monodisperse system and $<0,5$ for a polydisperse system. Lower PDI values show a better homogeneity of particle size. ${ }^{17}$ As shown in Figure. 2, the particle size distribution of F3 was the most homogeneous. PDI value of phytosome formulas F1, F2, F3, respectively, were $0.194 ; 0.227 ; 0.276$. Based on these results can be concluded that F1 had the highest particle size homogeneity since it had PDI value closest to zero (Figure 6).

Another important parameter that indicates system stability is zeta potential. Nanoparticles with zeta potentials above $+30 \mathrm{mV}$ and below - $30 \mathrm{mV}$ have good suspension stability since the charge on the surface prevents the aggregation between particles. The zeta potential values of F1, F2, and F3 were respectively; $-41.3,-47.9 \pm 3.43 ;-48.2 \pm 1.78$. The results showed that the three formulations could prevent aggregation between particles because they had a negative potential zeta value below $-30 \mathrm{mV}$.

F3 had the smallest particle size, this can be happen because of F3 had the most optimum lipoid content that made it able to absorb more EGCG. The nanovesicle formula with the optimum number of lipoids is known to produce vesicles of the smallest size and the narrowest particle size distribution. ${ }^{18}$ Thus, it can explain why F3 had the smallest particle size and PDI value, and the best potential zeta value compared to other formulas.

\section{Fourier Transform Infrared (FTIR) spectroscopy}

There was a decrease in intensity in $\mathrm{OH}$ peak of freeze-dried phytosome, compared with green tea leaf extract and Lipoid P 30 alone. This proves that there was a complex formed through the formation of hydrogen bonds between the extract and Lipoid. However, in the mechanical mixture spectrum between the extract and Lipoid, there was no decrease in the intensity of $\mathrm{OH}$ peak, this indicated the absence of chemical bonds between the two compound. 


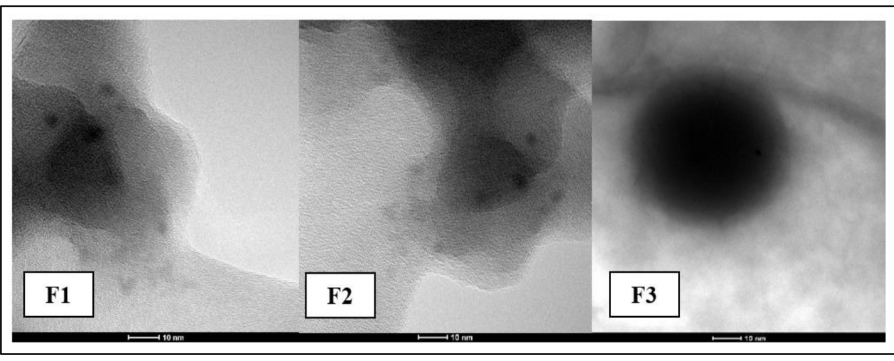

Figure 1: Morphology of phytosome vesicles.

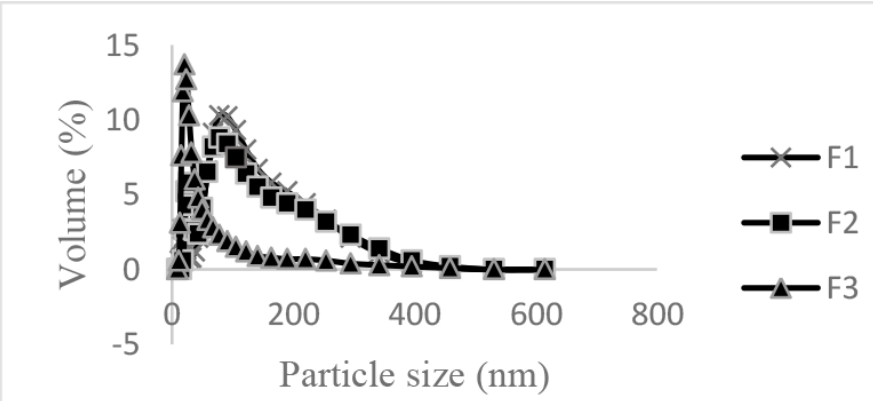

Figure 2: The particle size distribution curve of each phytosome formula.

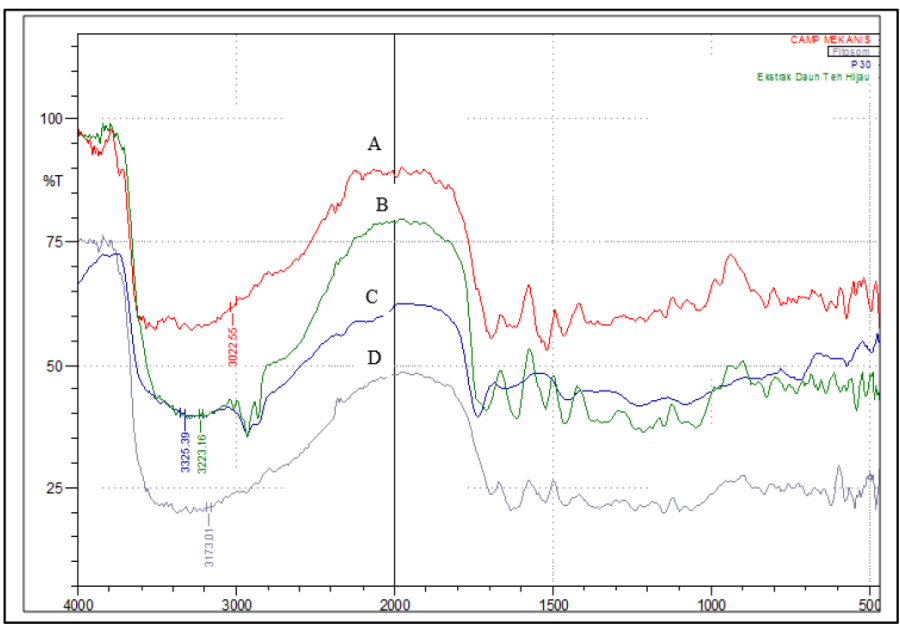

Figure 3: FTIR spectra of (A) the mixture of Lipoid $P 30$ and green tea leaf extracts,(B) green tea leaf extracts, (C) Lipoid P 30, and (D) Phytosome.

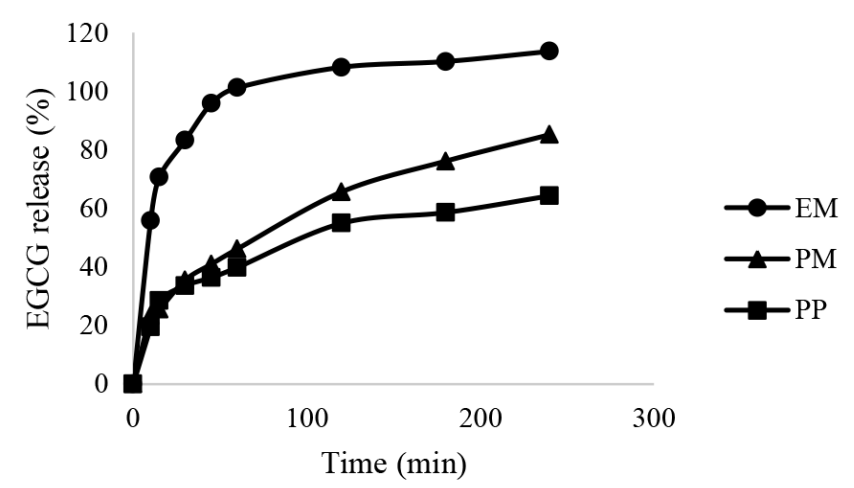

Figure. 4: EGCG release (\%) of EM, PM, and, PP.

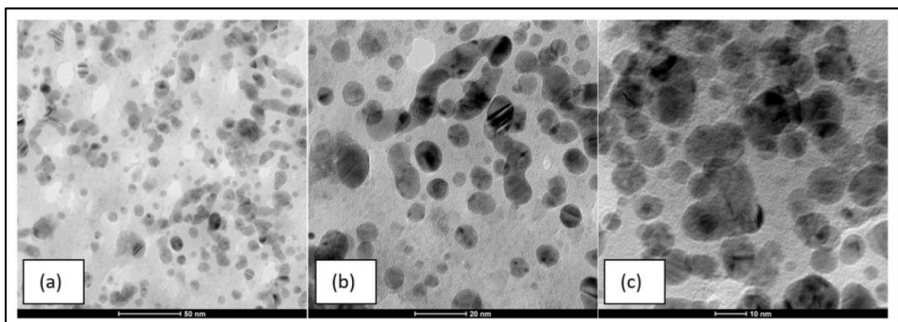

Figure 5 : The morphology of the phytosome vesicles on dissolution sampling results

\section{The Entrapment Efficiency of Phytosome and Phytosome-Loaded Microspheres}

Based on these results, it can be concluded that the entrapment efficiency increased with increasing number of lipoid. The more lipoids added in the formulation, the more EGCG entrapped by the lipoid. ${ }^{19}$ Formula with the highest entrapment efficiency will be selected to be combined into microspheres as it will have the fewest free extract that was not entrapped in the phytosomes thus making it more efficient. Furthermore, the microspheres formed had an entrapment efficiency of $53.45 \pm 2.11 \%$.

\section{Particle Size and Morphology of Microspheres}

The results indicated that microsphere powders were still in the range of microsphere size $(500 \mathrm{~nm}-20,000 \mathrm{~nm}) .^{20}$ The particle size distribution showed that the particles were distributed homogeneously that was supported by the PDI value below 0.5 . The morphology of Microspheres can be seen in Figure 7. The less spherical size may be caused by the use of polysaccharides as microsphere-forming agents ${ }^{27}$ Based on the morphology of the microspheres, it appears that the microspheres are not porous and some of them are attached to other microspheres, this may be due to the high viscosity in the solution to be dried by spray dryer. $^{28}$

\section{Degree of Swelling of Microspheres}

From the results can be interpreted that swelling index of Phytosome Powder (PP) $>$ Phytosome Microspheres $(\mathrm{PM})>$ Extract Microspheres (EM). The low swelling index of EM might be due to the dissolution of maltodextrin and gum arabic as the excipients of the microsphere. This was supported by EM dissolution result that released the highest amount of EGCG, followed by PM and PP.

\section{In vitro drug release studies}

The release of PM and PP that was lower than EM may be due to the presence of complexes between green tea leaf extract and phospholipids, which caused more time for green tea leaf extracts to escape from the microspheres. ${ }^{21}$ However, when compared with PP, PM showed a faster release. This may be due to the high solubility of maltodextrin and the hydrophilicity of gum arabic in the dissolution medium. ${ }^{22}$

Dissolution solution sample at $45 \mathrm{~min}$ was chosen to be evaluated using TEM to observe phytosome in the microsphere. The morphology analysis was done using a scale of $50 \mathrm{~nm}, 20 \mathrm{~nm}$, and $10 \mathrm{~nm}$. In the images can be seen that microsphere had already disintegrated and the phytosome vesicle morphology didn't have much difference compared to TEM images of phytosome suspension. This confirmed that formulating phytosome into microsphere did not disturb the integrity and structure of phytosome itself. The morphology obtained can be seen in Figure 5. 


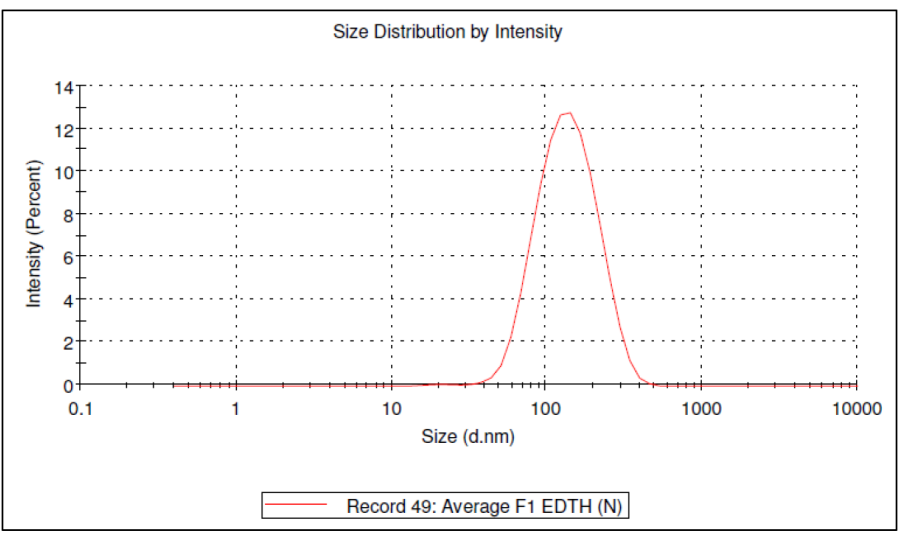

Figure. 6: The phytosome particle analysis graph of F1

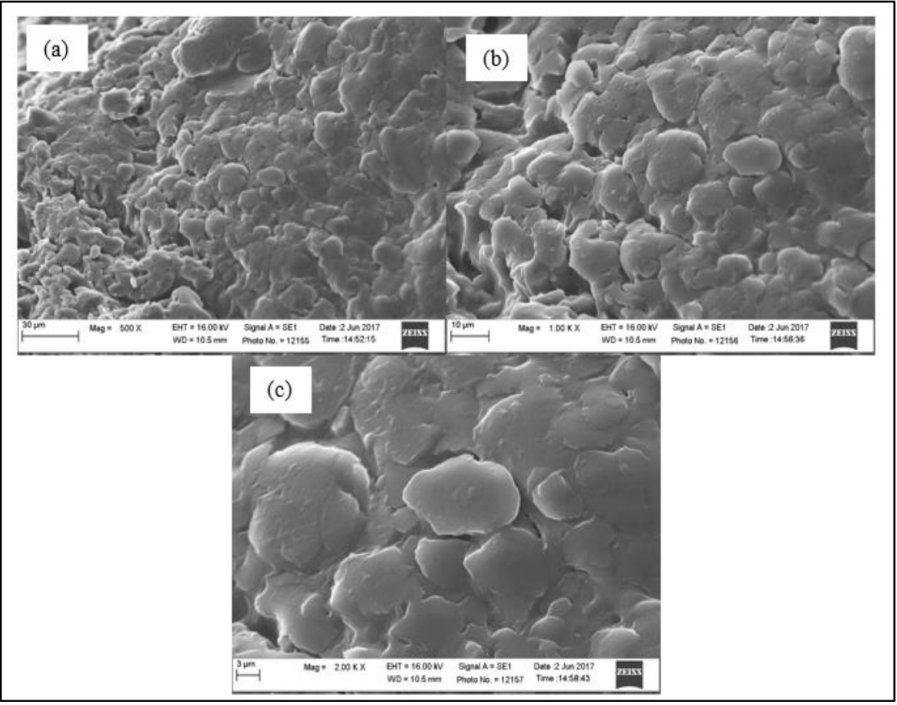

Figure. 7: The morphology of Microsphere

\section{Stability Study of Microspheres Antioxidant Activity}

PM had the smallest mean change of 0.03 . Therefore, compared to other temperatures, microsphere had the highest stability in $28^{\circ} \mathrm{C}$. This corresponded to moisture content analysis that microsphere had the highest water content at $4^{\circ} \mathrm{C}$, so it tended to be unstable. The increase of $\mathrm{IC}_{50}$ value can be caused by the increase of water content in the preparation that increased the instability of EGCG that is susceptible to oxidation. ${ }^{10}$

\section{Moisture Content}

Moisture content analysis was done to measure the ability of microsphere excipients in protecting active ingredient or preparation from environmental humidity. Products in the form of powder with low moisture content had a great resistance against microbiological damage because the water that is required for microorganisms to live and grow is limited. ${ }^{23}$ The water content can be caused by aqua demineralisata in the microsphere making process and also high degree of humidity.

After the 6th week, PM had higher moisture content than PP. This might be due to gum arabic that was used as one of microsphere excipients. Gum Arabic is a hygroscopic molecule that has a high molecular weight, complex molecular structure, and mostly consisting of starch. This made the water tend to be retained inside rather than evaporated. ${ }^{24}$ In Table 6 can also be seen that the decrease of storage temperature, the moisture content in both PM and PP tend to increase. During the temperature drop, the water vapor absorbing capacity of the powder will increase because it will increase the amount of bonded water content that will increase the water activity. ${ }^{25}$ However, the moisture content possessed by both the PM and PP suspension were still within the safe limits of the pharmaceutical dosage form which should be $\leq 10 \%{ }^{26}$

\section{CONCLUSION}

It can be concluded that phytosome-loaded microspheres can maintain good EGCG stability

\section{ACKNOWLEDGEMENT}

The authors are highly thankful to Universitas Indonesia who had given a financial support for this research, particularly for PITTA Research Grants 2017.

\section{CONFLICT OF INTEREST}

Authors declare that there is no conflict of interest.

\section{REFERENCES}

1. Ministry of Agriculture. The Development of Indonesian Tea Market in Domestic Market and International Market. 2014.

2. www.umm.edu. University of Maryland Medical Center (UMMC): Greene Street, Baltimore MD. 2017. Updated 2017; cited 2017 May 22. Available from http://www.umm.edu/health/medical/altmed/herb/green-tea

3. Higdon J, Frei B. Tea Catechins and Polyphenols: Health Effects, Metabolism, and Antioxidant Functions. Critical Reviews in Food Science and Nutrition. 2003;43(1):89-143.

4. Patel AR, Velikov KP. Non-covalent interactions of green tea polyphenols: Source of novel colloidal structures. Nova Biomedical. 2013;151-66.

5. Legeay S, Rodier M, Fillon L, Faure S, Clere N. Epigallocatechin gallat: A review of its beneficial properties to prevent metabolic syndrome. Nutrients. 2015;7(7):5443-68.

6. Kidd P. Bioavailability and Activity of Phytosome Complexes from Botanical Polyphenols: The Silymarin, Curcumin, Green Tea, and Grape Seed Extracts. Alternative Medicine. 2009;14(3):226-46.

7. Lambert J, Sang S, Yang C. Biotransformation of Green Tea Polyphenols and the Biological Activities of Those Metabolites. Molecular Pharmaceutics. 2007;4(6):819-25

8. Sabzichi M, Hamishehkar H, Ramezani F, Sharifi S, Tabasinezhad M, Pirouzpanah M. et al. Luteolin-loaded Phytosomes Sensitize Human Breast Carcinoma MDA-MB 231 Cells to Doxorubicin by Suppressing Nrf2 Mediated Signalling. Asian Pacific Journal of Cancer Prevention. 2014;15(13):5311-6.

9. Karimi N, Ghanbarzadeh B, Hamishehkar H. Phytosome and Liposome: The Beneficial Encapsulation Systems in Drug Delivery and Food Application. Applied Food Biotechnology. 2015;2(3):17-27.

10. Munin A. Edwards-Lévy F. Encapsulation of Natural Polyphenolic Compounds a Review. Pharmaceutics. 2011;3(4):793-829.

11. Jain G, Khar RK, Ahmad FJ. Theory and Practiceof Physical Pharmacy, London Elsevier. 2011:459-70.

12. Gadkari P, Balaraman M. Catechins: Sources, extraction and encapsulation: A review. Food And Bioproducts Processing. 2015;93:122-38.

13. Rocha S, Generalov R, Pereira M, Peres I, Juzenas P, Coelho M. Epigallocatechin gallate-loaded polysaccharide nanoparticles for prostate cancer chemoprevention. Nanomedicine. 2011;6(1):79-87.

14. Surinut $P$, Kaewsutthi $S$, Surakarnkul R. Radical Scavenging Activity in Fruit Extracts. Acta Horticulturae. 2005;(679):201-3.

15. Bhattacharya S. Phytosomes: The New Technology for Enhancement of Bioavailability of Botanicals and Nutraceuticals. International Journal of Health Research. 2009;2(3):225-32

16. Tung B, Hai N, Son P. Hepatoprotective effect of Phytosome Curcumin against paracetamol-induced liver toxicity in mice. Brazilian Journal of Pharmaceutical Sciences. 2017;53(1):1-13

17. Malvern Instruments. Dynamic Light Scattering Common Terms Defined 2011;1-6.

18. Suriyakala P, Satheesh Babu N, Senthil Rajan D, Prabakaran L. Phospholipids as Versatile Polymer in Drug Delivery Systems. International Journal of Pharmacy and Pharmaceutical Sciences. 2014;6(1):8-11. 
19. Keerthi DP. Formulation and Evaluation of Capsules of Ashwagandha Phytosomes. 2014.

20. Sinko PJ. Martin: Farmasi Fisika dan IImi Farmasetika (5 ed.). EGC. 2006.

21. Zhang J, Tang Q, Xu X, Li N. Development and evaluation of a novel phytosomeloaded chitosan microsphere system for curcumin delivery. International Journal of Pharmaceutics. 2013;448(1):168-74.

22. Zokti J, Baharin B, Mohammed A, Abas F. Green Tea Leaves Extract: Microencapsulation, Physicochemical and Storage Stability Study. Molecules. 2016;21(8):940.

23. Farkye N, Smith K, Schonrock FT. An Overview of Changes in the Characteristics, Functionality and Nutritional Value of Skim Milk Powder (SMP) During Storage. Journal of Dairy Science. 2001.

24. Hadiwiyoto S, Mutri C. Pengaruh Dekstrin dan Gum Arab terhadap Sifat Kimia dan Fisik Bubuk Sari Jagung Manis (Zea mays saccharata). Jurnal Teknologi Dan Industri Pangan. 2010;21(2):102-7.

25. Arizka A, Daryatmo J. Perubahan Kelembabandan Kadar Air Teh Selama Penyimpanan pada Suhu dan Kemasan yang Berbeda. Jurnal Aplikasi Teknologi Pangan. 2015:4(4):124-9.

26. Badan Pengawas Obat dan Makanan. Peraturan Kepala Badan Pengawas Obat dan Makanan Republik Indonesia tentang Persyaratan Mutu Obat Tradisional. BPOM. 2014.

27. Peres I. Encapsulation of Active Compounds: Particle Characterization, Loading Efficiency and Stability (Ph.D). University of Porto. 2011.

28. Lacasse F, Hildgen P, McMullen J. Surface and morphology of spray-dried pegylated PLA microspheres. International Journal of Pharmaceutic. 1998:174 $(1-2): 101-9$.

Article History: Submission Date : 28-11-2017 ; Revised Date : 17-12-2017; Acceptance Date : 08-01-2018

Cite this article: Anwar E, Farhana N. Formulation and Evaluation of Phytosome-Loaded Maltodextrin-Gum Arabic Microsphere System for Delivery of Camellia sinensis Extract. J Young Pharm. 2018;10(2)Suppl:s56-s62. 